Acta Theriologica 45 (2): 233-242, 2000.

PL ISSN 0001-7051

\title{
Seasonal variation in the feeding habits of riparian mustelids in river valleys of $\mathrm{NE}$ Belarus
}

\author{
Vadim E. SIDOROVICH
}

Sidorovich V. E. 2000. Seasonal variation in the feeding habits of riparian mustelids in river valleys of NE Belarus. Acta Theriologica 45: 233-242.

In 1986-1997, diet composition of the native riparian mustelids: the otter Lutra lutra (Linnaeus, 1758), the European mink Mustela lutreola (Linnaeus, 1761), the polecat $M$. putorius (Linnaeus, 1758), and the naturalized one, the American mink M. vison (Schreber, 1777) was studied in relation to seasonal changes of the habitats (the Lovat river, NE Belarus). Amphibians, fish, crayfish, small mammals, and birds appeared the essential prey resources supporting the guild of riparian mustelids. In the river valleys, the two mink species and polecat were characterized by opportunistic feeding habits, whereas the otters specialised on fish. In spring and autumn, frogs were important prey to all mustelids studied. The trophic niches of the two mink species were wider than those of the otter and the polecat. In the seasonally changing environmental conditions, the American mink appeared a more opportunistic predator than the European mink. Food niches of the three native mustelids overlapped notably less with each other (Pianka's $\alpha$ from 0.24 to 0.70 ) than with the American mink ( $\alpha$ from 0.60 to 0.89 ). The obtained data suggest that in river valley habitats the naturalized American mink may be a strong competitor for prey with the native riparian mustelids, especially the European mink and the polecat.

Vertebrate Predation Research Group, Institute of Zoology, National Academy of Sciences of Belarus, Akademicheskaya str. 27, Minsk - 220072, Belarus

Key words: Lutra lutra, Mustela lutreola, Mustela putorius, Mustela vison, diet composition, food niche overlaps, environmental variation

\section{Introduction}

There are many studies on the diet of the otter Lutra lutra (Mason and Macdonald 1986, Kruuk 1995, Sidorovich 1997, Jędrzejewska and Jędrzejewski 1998), the American mink Mustela vison (Tumanov and Smelov 1980, Dunstone 1993, Sidorovich 1997, Jędrzejewska and Jędrzejewski 1998) and the polecat $M$. putorius (Danilov and Tumanov 1976, Tumanov and Smelov 1980, Blandford 1987, Weber 1989, Lode 1990, Jędrzejewski et al. 1993, Sidorovich 1997). Fewer studies were conducted on the feeding habits of the European mink M. lutreola (Danilov and Tumanov 1976, Tumanov and Smelov 1980, Sidorovich 1992, 1997, Sidorovich et al. 1998), and still fewer studies compared the feeding habits of the native riparian mustelids with those of the naturalized American mink (Danilov and Tumanov 1976, Tumanov and Smelov 1980, Sidorovich 1992, 1997, Sidorovich et al. 1998). 
The aims of this study were to: (1) compare the feeding habits of the entire guild of riparian mustelids on a seasonal basis; (2) describe and compare the variation in mustelid diets during the short-lasting periods of unfavourable ambient conditions, such as strong frosts, spring flood, and summer drought.

\section{Study area}

Data were collected at the upper reaches of the Lovat river in north-eastern part of Belarus $\left(56^{\circ} \mathrm{N}\right.$, $32^{\circ} \mathrm{E}$, Gorodok district, Vitebsk region) in 1986-1997. There are two main types of small rivers in the upper reaches of the Lovat. The first are fast flowing streams with high, steep, wooded banks, and with small flood-plains. River widths vary between 5 and $8 \mathrm{~m}$ and their depths between 0.5 and $1.5 \mathrm{~m}$. The second type are slowly flowing, small rivers with rather wide $(0.2-1 \mathrm{~km})$, swamped flood-plains. River widths vary between 7 and $25 \mathrm{~m}$ and their depths between 1 and $2.5 \mathrm{~m}$. River banks are usually marshy. The material on riparian mustelids was collected only in river valleys as main type of their habitats, and not in other habitats, such as glacial lakes, brooks, and marshes.

In the study area, floods occur each spring. Normally, turbid waters flood the whole river valleys. Spring flood lasts for three weeks or longer. Summer droughts are recorded once per 4-6 years. During the drought, all brooks and fast flowing small rivers dry up. Usually, several periods with strong frost are observed every winter in the study area. During this harshest period, all streams and lakes are ice-bound. Water temperature is $0.5-1^{\circ} \mathrm{C}$, air temperature drops to $-20^{\circ} \mathrm{C}$ or even $-30^{\circ} \mathrm{C}$. Strong frost may continue for 1-3 weeks.

\section{Material and methods}

Scats of European and American mink species were collected on a regular basis from their main dens, where the identity of the occupant was known from live-trapping, radio-tracking, trapping, or visual observations. In winter, many scats were collected at the mustelid tracks close to their main dens, or at fresh tracks of the radio-tracked animals. In cases, when the naturalized and the native mink inhabited adjacent territories, I checked tracks and distinguished them according to the specific features (Sidorovich 1999). Otter spraints were only collected adjacent to their tracks. Totally, I collected 2347 scats and 19 stomachs and intestines of European mink, 2813 scats and 56 alimentary tracts of American mink, 1117 spraints and 6 alimentary tracts of otter, and 672 scats and 22 alimentary tracts of polecats. The whole material was analysed to determine as many different prey individuals as possible by means of both species identification and size differences. Prey were identified by micromammalian teeth (Pucek 1981) and hair (Debrot et al. 1982), amphibian bones (Böhme 1977, Marz 1987), fish scales, teeth, and vertebrates (Galkin 1953, Zhukov 1965, 1988, Marz 1987, Steinmetz and Muller 1991), reptilian bones and skins (Marz 1987), and bird feathers. Insects, crayfish, and molluses were distinguished by their hard covers. The number of different prey individuals found in all feeding samples of a given predator species was taken as $100 \%$, and percentages of various prey groups were calculated. To compare the food niche breadths of the four mustelids, $B$ index was calculated according to Levins (1968): $B=1 / \Sigma p_{i}{ }^{2}$, where $p_{i}$-fraction of a given prey group in a predator's diet. $B$ varies from 1 (the narrowest niche) to the maximum number of prey groups used for calculations (the broadest niche possible). In order to evaluate an overlap of food niches, Pianka's (1973) index $\alpha$ was calculated, which varies from 0 (exclusive niches) to 1 (complete overlap):

$$
\alpha_{i j}=\left(\Sigma p_{i a} \times p_{j a}\right) \times\left[\left(\Sigma p_{i a}{ }^{2}\right) \times\left(\Sigma p_{j a}{ }^{2}\right)\right]^{-1 / 2},
$$

where $\alpha_{i j}$ is the overlap between species $i$ and $j, p_{i a}$ is the fraction of $a$ th prey group in the diet of $i$ th predator, and $p_{j a}$ is the fraction of ath prey group in the diet of $j$ th predator. 


\section{Results}

\section{Seasonal trends in the diet of riparian mustelids}

Fig. 1 shows the changes in the occurrence of the main prey categories in the diets of the riparian mustelids in the Lovat river valley. The otter diet was dominated by fish $(39-80 \%$ of prey in various months, mean $60 \%$ ) and supplemented with amphibians and crayfish. In April and October-November, the consumption of amphibians by otters increased and that of fish declined compared to other months (Fig. 1). Generally, however, the seasonal variation in otter diet was fairly small. The polecat relied on two major resources: small mammals (from

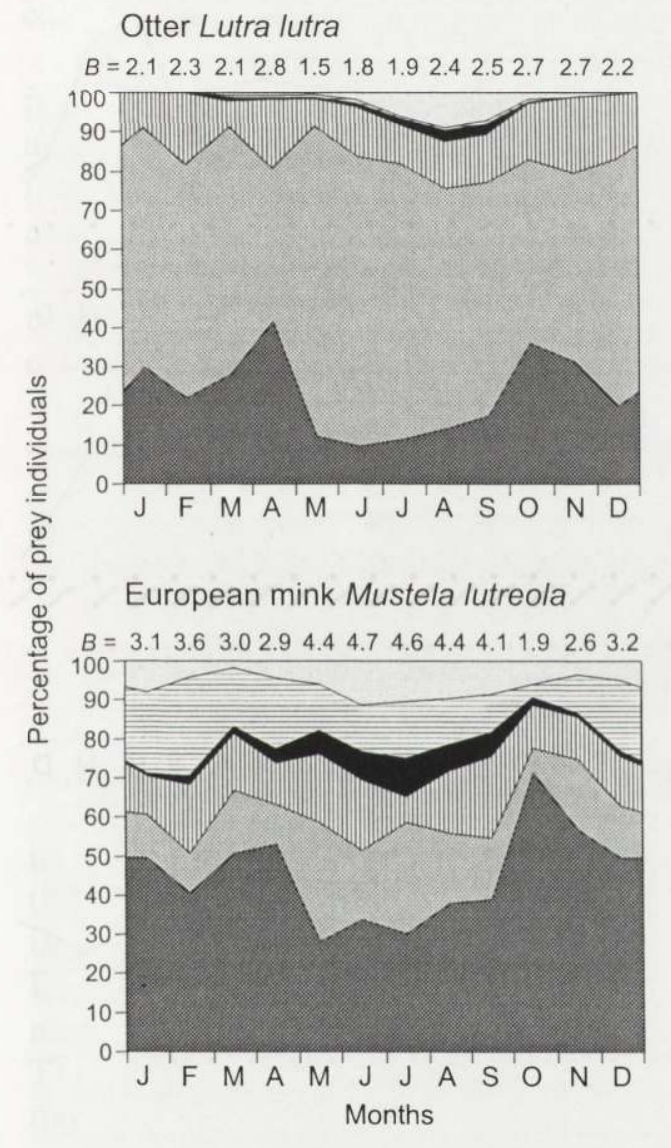

\section{Polecat Mustela putorius}

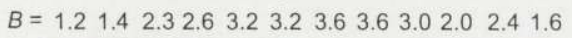

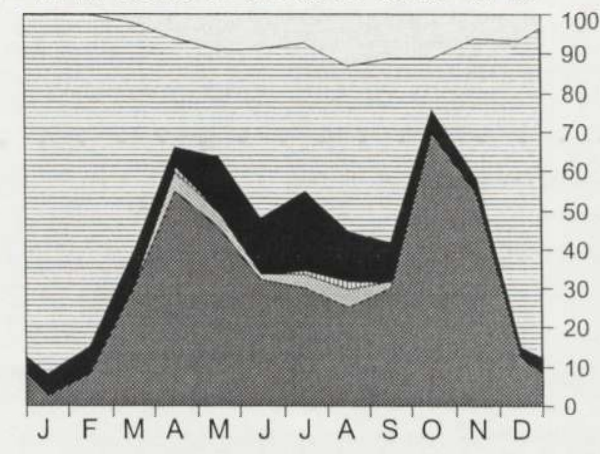

American mink Mustela vison

$B=\begin{array}{lllllllll}1.5 & 2.5 & 3.22 .6 & 3.0 & 4.3 & 4.45 & 5.54 .01 .92 .63 .1 \\ 100 & \end{array}$

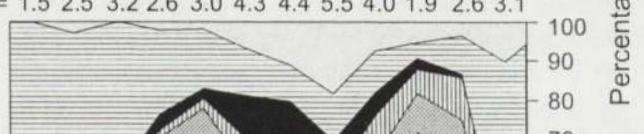

Amphibians

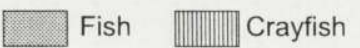

Birds

Fig. 1. Seasonal changes in the diets of the riparian mustelids in the Lovat river head (in percentages of occurrence of the main prey categories). Total numbers of prey individuals recovered from scats: otter - 2832, European mink - 4324, American mink - 52633, polecat - 1330. B - monthly index of food niche breadth (after Levins 1968). 
14 to $92 \%$ of prey, mean $49 \%$ ) and amphibians (3-69\%, mean $33 \%$ ), and supplemented its diet with birds. In their feeding habits, polecats showed a strong seasonal shift: in winter they hunted predominantly small mammals, in spring and autumn amphibians, and in summer they had a diversified diet of mammals, frogs, and birds (Fig. 1). The European mink fed predominantly on amphibians (from 29 to $72 \%$ in various months, mean $45 \%$ of prey) and it exploited fish, crayfish, and small mammals (Fig. 1). Besides the summer increase in the consumption of fish and spring and autumn peaks in the consumption of amphibians, the seasonal
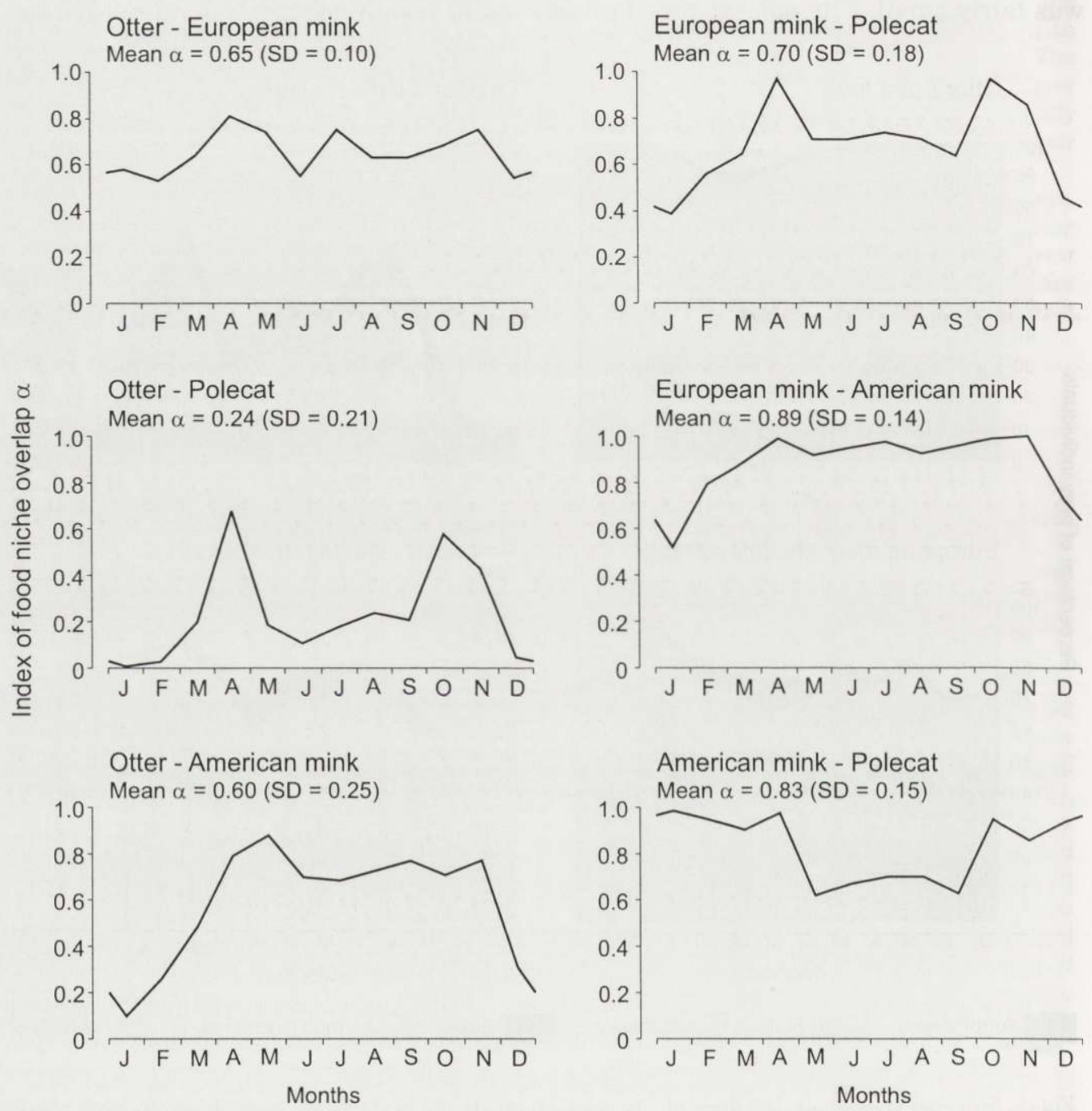

Fig. 2. Seasonal variation in food niche overlaps between all possible pairs of riparian mustelids. Pianka's index $\alpha$ calculated for six prey groups (shown in Fig. 1). 
variation in European mink diet was not large. Two resources played the essential role in the diet of American mink, amphibians (from 14 to $72 \%$, mean $37 \%$ ) and small mammals (4-80\% in various months, mean $27 \%$ ). Supplementary prey groups were fish and crayfish. Seasonal variation in American mink diet was manifest and characterized by strong predominance of small mammals in winter, their intense preying on amphibians in spring and autumn, and a diverse array of prey taken in summer (Fig. 1). Generally, three seasonal trends were apparent in the diets of the riparian mustelids: (1) an increase in the proportion of frogs in the diets of all predators in April and October-November; (2) an increase in the proportion of fish in the diets of otter and the two mink species in May-August; (3) an increase in the proportion of small mammals in the diets of the two mink species and polecat in the cold season (November-March).

Of the four species analysed, the otter had the narrowest food niche (monthly $B$ from 1.5 to 2.8 , mean 2.3; Fig. 1). Polecat's niche breadth varied from 1.2 to 3.6 , on average 2.5. The two mink species were characterised by much wider niches: $B$ from 1.9 to 4.7 , on average 3.5 in the European mink, and from 1.5 to 5.5, on average 3.2 in the American mink (Fig. 1).

Seasonal variation in the food niche overlaps between all possible pairs of mustelids is shown in Fig. 2. Generally, in all pairwise comparisons, the dietary overlaps were highest in spring and autumn (due to high proportions of amphibians in the diets of all studied predators), and except for the pair American mink-polecat, they markedly declined in winter. Furthermore, the dietary overlaps among the native predators were not high ( $\alpha$ from 0.24 to 0.70 ), whereas the food niche of the non-native American mink heavily overlapped with those of other mustelids, especially the European mink and the polecat (Fig. 2).

\section{Long-term periods of strong frost}

The diets of the riparian mustelids during the strong frost period are presented in Table 1. During that harsh period, the European mink mainly preyed on frogs (50.7\% of prey). Other food categories (small mammals, fish, and crayfish) were less important. In contrast, the American mink specialized on small mammals (80.6\%). Despite unfavourable conditions for hunting aquatic prey, the native European mink consumed fewer small mammals (21.8\%) than the American mink (Table 1). The difference was highly significant $(G=35.9, p<0.01)$. The trophic niche was narrow in the American mink and much wider in the European mink.

Polecats living in river valleys were characterized by feeding habits very similar to those of the American mink (Table 1). Polecat diet was dominated by small mammals (95.3\% of prey) and it overlapped considerably with that of the American mink ( $\alpha=0.98)$ but not the European mink $(\alpha=0.38)$. In the periods of strong frosts, otters fed mainly on fish $(61.2 \%$ of prey; Table 1$)$ and their diet overlapped notably with that of the European mink $(\alpha=0.61)$. 
Table 1. Diet composition (expressed in percentage of prey individuals recovered from scats) of the riparian mustelids during periods of strong frost, the Lovat river, Belarus, 1986-1995. $n$-number of prey specimens found in scats, $B$ - index of food niche breadth (after Levins 1968), $\alpha$-index of food niche overlap after Pianka (1973). Both $B$ and $\alpha$ were calculated for the six listed groups of prey.

\begin{tabular}{lcccc}
\hline Prey type & $\begin{array}{c}\text { Otter } \\
(n=57)\end{array}$ & $\begin{array}{c}\text { European mink } \\
(n=138)\end{array}$ & $\begin{array}{c}\text { American mink } \\
(n=201)\end{array}$ & $\begin{array}{c}\text { Polecat } \\
(n=63)\end{array}$ \\
\hline Insects & - & 5.8 & - & - \\
Crayfish Astacus astacus & 8.8 & 7.2 & 3.0 & - \\
Fish & 61.2 & 13.8 & 2.0 & - \\
Frogs & 30.0 & 50.7 & 13.4 & - \\
Birds & - & 0.7 & 1.0 & 4.7 \\
Small mammals & - & 21.8 & 80.6 & 95.3 \\
& & & & 1.1 \\
Index of food niche breadths $B$ & 2.1 & 3.0 & 1.5 & 0 \\
Index of food niche ovelap $\alpha:$ & - & 0.61 & 0.10 & 0.38 \\
Otter & & - & 0.53 & 0.98 \\
European mink & & & - & \\
American mink & & & &
\end{tabular}

\section{Spring flood}

The diets of the riparian mustelids during spring flood in the Lovat river valley are shown in Table 2. In the changing conditions of spring flood, minks and polecats live around the flooded river valleys. The diets of the two mink species and the polecat were dominated by frogs (50-56.1\% of prey), mainly the common frog Rana temporaria. Otters fed on fish and frogs (about $40 \%$ each). Among fish taken by the otter as well as other riparian mustelids, the pike Esox lucius predominated. Small mammals were an important resource to the two mink species and the polecat, whereas crayfish to the otters and the European mink (Table 2). During the spring flood, the diets of all predators ovelapped extensively ( $\alpha$ from 0.79 to 0.98 ; Table 2 ).

\section{Summer drought}

In July-August 1992, there was a severe drought in the Lovat river head. To analyse differences in the diets of the riparian mustelids during the drought, comparisons were made with data from the normal summer of 1991 (Table 3). Otters were not considered; during the drought they usually left the dried small rivers and moved to the glacial lakes.

The diet of the European mink did not change much during the drought, compared to normal summer; aquatic prey (fish and crayfish) constituted one-third of its prey, though the proportions of fish and crayfish changed (Table 3 ). In the diet of American mink, the role of aquatic prey declined over 2 -fold (from 39.1 to $15.6 \%$ ) and the share of small mammals increased (from 20.8 to $40.5 \%$ ). Amphibians, small mammals and birds were the most important prey for the polecats both 
Table 2. Diet composition of the riparian mustelids (expressed in percentages of prey individuals recovered from scats) during the periods of spring floods, the Lovat river head, Belarus, 1989-1995. Denotations as in Table 1. $B$ and $\alpha$ calculated for the seven listed groups of prey.

\begin{tabular}{lcccc}
\hline Prey type & $\begin{array}{c}\text { Otter } \\
(n=112)\end{array}$ & $\begin{array}{c}\text { European mink } \\
(n=154)\end{array}$ & $\begin{array}{c}\text { American mink } \\
(n=263)\end{array}$ & $\begin{array}{c}\text { Polecat } \\
(n=40)\end{array}$ \\
\hline Insects & - & 6.5 & 1.9 & 5.0 \\
Crayfish Astacus astacus & 17.9 & 10.4 & 2.3 & - \\
Fish & 39.4 & 9.9 & 14.4 & 7.5 \\
Frogs Rana spp. & 41.8 & 53.5 & 56.1 & 50.0 \\
Toads Bufo spp. & - & - & 0.6 & 5.0 \\
Birds & 0.9 & 2.0 & 3.0 & 5.0 \\
Small mammals & - & 17.7 & 21.7 & 27.5 \\
Index of food niche breadth B & 2.8 & 2.9 & 2.6 & 2.9 \\
Index of food niche overlap $\alpha:$ & - & & & \\
Otter & - & - & 0.79 & 0.68 \\
European mink & & & 0.98 & 0.96 \\
American mink & & & - & 0.98 \\
\hline
\end{tabular}

Table 3. Diet composition of the family groups (adult females with kittens) of European mink, American mink, and polecat (expressed in percentages of prey individuals recovered from scats) during the normal summer (August 1991) and during the summer drought (August 1992), the Lovat river head. Denotations as in Table 1 . Indices $B$ and $\alpha$ calculated for the 10 listed groups of prey.

\begin{tabular}{|c|c|c|c|c|c|c|}
\hline \multirow[b]{2}{*}{ Prey type } & \multicolumn{2}{|c|}{ European mink } & \multicolumn{2}{|c|}{ American mink } & \multicolumn{2}{|c|}{ Polecat } \\
\hline & $\begin{array}{l}\text { Normal } \\
\text { summer } \\
(n=251)\end{array}$ & $\begin{array}{c}\text { Dry } \\
\text { summer } \\
(n=402)\end{array}$ & $\begin{array}{l}\text { Normal } \\
\text { summer } \\
(n=294)\end{array}$ & $\begin{array}{c}\text { Dry } \\
\text { summer } \\
(n=511)\end{array}$ & $\begin{array}{l}\text { Normal } \\
\text { summer } \\
(n=46)\end{array}$ & $\begin{array}{c}\text { Dry } \\
\text { summer } \\
(n=210)\end{array}$ \\
\hline Insects & 9.6 & 5.7 & 5.4 & 6.8 & 8.7 & 7.1 \\
\hline Molluscs & 2.0 & 5.0 & 0.7 & 1.0 & 4.3 & 4.8 \\
\hline Crayfish Astacus astacus & 16.3 & 4.5 & 10.2 & 1.6 & - & 1.9 \\
\hline Fish & 17.8 & 33.1 & 28.9 & 14.0 & - & 7.1 \\
\hline Frogs Rana spp. & 36.3 & 37.3 & 23.6 & 20.5 & 21.7 & 17.6 \\
\hline Toads Bufo spp. & 2.0 & 0.5 & 1.3 & 3.5 & 4.3 & 19.0 \\
\hline Reptiles & 0.4 & 0.7 & 2.0 & 4.3 & 4.3 & 4.8 \\
\hline Birds & 2.8 & 2.0 & 5.8 & 7.8 & 15.2 & 8.6 \\
\hline Small mammals & 12.4 & 11.2 & & & & \\
\hline Fruit and herbs & 0.4 & - & 1.3 & - & - & - \\
\hline $\begin{array}{l}\text { Index of food niche breadth } B \\
\text { Index of food niche overlap } \alpha \text { : }\end{array}$ & 4.6 & 3.7 & 5.0 & 4.2 & 3.9 & 5.7 \\
\hline European mink & - & - & 0.90 & 0.69 & 0.62 & 0.61 \\
\hline American mink & & & - & - & 0.68 & 0.90 \\
\hline
\end{tabular}


during the dry and the normal summer (Table 3). Interestingly, among amphibians captured by polecats, frogs predominated in the normal summer, whereas toads during the drought.

There was no consistent pattern in the changes of predators' food niche breadths between the dry and the normal summers (Table 3 ). As regards overlaps of food niches, worth noting is the American mink: during the normal summer its diet was most similar to that of the European mink, while during the drought it markedly shifted towards the polecat's niche (Table 3 ).

\section{Discussion}

The presented data on feeding habits of the riparian mustelids showed that the seasonal changes in their diets were mainly caused by variation in abundance and availability of frogs and fish. In early spring, brown frogs concentrate at spawning sites (Pikulik 1985, Pikulik and Sidorovich 1991), and are easily available to predators. At the same time, water-living prey such as fish and crayfish are presumably less available in turbid flood waters that occur each spring. In autumn, common frogs again concentrate at stream banks and seek places for wintering in stream (Pikulik 1985). Availability of fish increases during their spawning season in May-July (Zhukov 1965), which was reflected by the summer increase in fish consumption by otter and mink.

In severe winters, when the access to river was limited due to ice cover, and air and water temperatures were low, the American mink hunted almost exlusively small mammals. In contrast, European mink continued to hunt in rivers; frogs (mainly the common frog) were their most important prey. Common frogs concentrate in streams for wintering, so the biomass of prey may be abundant there (Pikulik and Sidorovich 1991, 1996). For instance, during the winter of 1995-1996, the mean biomass of common frogs in the Lovat upper reaches was about $395 \mathrm{~kg}$ per $1 \mathrm{~km}$ of the river (Pikulik and Sidorovich 1996, Sidorovich 1997).

Feeding habits of the American mink were rather opportunistic. This was shown earlier for the American mink in many regions of North America (eg Eberhardt and Sargeant 1975, Arnold and Fritzell 1987) and Europe (Gerell 1967, Chanin and Linn 1980, Jenkins and Harper 1980, Kyne et al. 1989, Dunstone 1993, Sidorovich 1997, Sidorovich et al. 1998). For a semi-aquatic predator, feeding opportunism is a highly adaptive feature which improves its survival in unfavourable and variable conditions in river valleys. Therefore, the naturalized American mink appeared a more competitive predator than the native European mink. The latter one maintained more stable diet in spite of large variation in the abundance and availability of prey in aquatic habitats.

The polecat is also known for its opportunistic feeding habits (Blandford 1987, Weber 1989, Lode 1990, Jędrzejewski et al. 1993, Sidorovich 1997). However, the polecat is markedly more 'terrestrial' than mink and they inhabit habitats with different prey diversity, so it is difficult to compare its opportunism with those of 
the two mink species. Also, the data on diet at an individual level may be needed to investigate this problem.

This study provides little evidence for resource competition among the native riparian mustelids. However, it seems that the naturalized American mink may be a strong competitor to native species, especially to European mink and polecat. Nonetheless, the decline of European mink population in my study area was very quick, thus, feeding competition cannot be the sole factor responsible for such a fast decline (Sidorovich et al. 1995, Sidorovich 1997). Recently obtained data suggest that a direct, aggressive interference from the American mink towards the European mink is more likely to be the main factor responsible for the decline of the European mink in NE Belarus (Sidorovich et al. 1999).

Acknowledgement: I am grateful to the Institute of Zoology of the National Academy of Sciences (Belarus), the Darwin Initiative Foundation (Great Britain), and Soros Foundation, which supported this study. I thank Dr B. Jędrzejewska and two anonymous referees for their critical comments on the earlier drafs, and to K. Zub for drawing the figures.

\section{References}

Arnold T. N. and Fritzell E. K. 1987. Food habits of prairie mink during the waterfowl breeding season. Canadian Journal of Zoology 65: 2322-2324.

Blandford P. R. S. 1987. Biology of the polecat Mustela putorius: a literature review. Mammal Review 17: $155-198$.

Böhme G. 1977. Zur Bestimmung quartarer Anuen Europas an Hand von Skelettelementen. Wissenschaftliche Zeitschrift der Humboldt-Universität zu Berlin. Math-Naturwiss Reihe 26: 283-300.

Chanin P. R. F. and Linn I. J. 1980. The diet of the feral mink (Mustela vison) in southwest Britain. Journal of Zoology, London 192: 205-223.

Danilov P. I. and Tumanov I. L. 1976. [Mustelids of north-eastern of SSSR]. Nauka publisher, Leningrad: 1- 256. [In Russian]

Debrot S., Fivaz G., Mermod C. and Weber J.-M. 1982. Atlas de poils de mammiferes d'Europe. University of Neuchâtel, Switzerland.

Dunstone N. 1993. The mink. T. and A. D. Poyser Ltd., London: 1-232.

Eberhardt L. E. and Sargeant A. B. 1975. Mink predation on prairie marshes during the waterfowl breeding season. Proceeding of Predator Symposia, Missoula: 33-43.

Galkin G. G. 1953. [Atlas of scales of freshwater fishes]. Publications of the Research Institute of River and Lake Economy 16: 1-167. [In Russian]

Gerell R. 1967. Food selection in relation to habitat in mink (Mustela vison, Schreber) in Sweden. Oikos 18: 233-246.

Jenkins D. and Harper R. J. 1980. Ecology of otters in Northern Scotland. II. Analyses of otter (Lutra lutra) and mink (Mustela vison) faeces from Deeside, N.E. Scotland in 1977-78. Journal of Animal Ecology 49: 737-754.

Jędrzejewska B. and Jędrzejewski W. 1998. Predation in vertebrate communities. The Białowieża Primeval Forest as a case of study. Springer, Berlin: 1-450.

Jędrzejewski W., Jędrzejewska B. and Brzeziński M. 1993. Winter habitat selection and feeding habits of polecats (Mustela putorius) in Białowieża National Park, Poland. Zeitschrift für Säugetierkunde 58: 75-83.

Kruuk H. 1995. Wild otters. Predation and populations. Oxford University Press, Oxford: 1-290. 
Kyne M. J., Smal C. M. and Fairley J. S. 1989. The food of otters Lutra lutra in the Irish Midlands and a comparison with that of Mink Mustela vison in the same region. Proceeding of the Royal Irish Academy 89(3): 3-46.

Levins R. 1968. Evolution in changing environments. Princeton University Press., Princeton.

Lode T. 1990. Le regime alimentaire d'un petit Carnivore, le putois (Mustela putorius) dans l'ouest de la France. Gibier Faune Sauvage 7: 193-203.

Marz R. 1987. Gewoll- und Rupfungskunde. Akademie Verlag, Berlin: 1-398.

Mason C. F. and Macdonald S. M. 1986. Otters. Ecology and conservation. Cambridge University Press, Cambridge: 1-236.

Pianka E. R. 1973. The structure of lizard communities. Annual Review of Ecology and Systematics 4 : 53-74.

Pikulik M. M. 1985. [Amphibians of Belarus]. Nauka and Tekhnika, Minsk: 1-190. [In Russian]

Pikulik M. M. and Sidorovich V. E. 1991. Estimation of structural and functional inter-population relationships of semi-aquatic mustelids and amphibians in Belarus. Ecology (Sverdlovsk) 6: 28-36. [In Russian with English summary]

Pikulik M. M. and Sidorovich V. E. 1996. Relationship between seasonal dynamics of amphibian distribution and otter reproduction. Reports of National Academy of Sciences of Belarus 40: 80-83. [In Russian with English summary]

Pucek Z. [ed] 1981. Keys to vertebrates of Poland. Mammals. Polish Scientific Publishers, Warszawa: $1-367$.

Sidorovich V. E 1992. Comparative analysis of the diets of European mink (Mustela lutreola), American mink (M. vison) and polecat (M. putorius) in Byelorussia. Small Carnivore Conservation 6: 2-4.

Sidorovich V. E. [ed] 1997. Mustelids in Belarus. Evolutionary ecology, demography and interspecific relationships. Zolotoy Uley Publisher, Minsk: 1-289.

Sidorovich V. E. 1999. How to identify mustelid tracks. Small Carnivore Conservation 20: 22-27.

Sidorovich V. E., Kruuk H. and Macdonald D. W. 1999. Body size, and interactions between European and American mink (Mustela lutreola and M. vison) in Eastern Europe. Journal of Zoology, London 248: 521-527.

Sidorovich V. E., Kruuk H., Macdonald D. W. and Maran T. 1998. Diets of semi-aquatic carnivores in northern Belarus, with implications for population changes. [In: Behaviour and ecology of riparian mammals. N. Dunstone and M. Gorman, eds]. Symposia of the Zoological Society of London, Cambridge University Press: 177-190.

Sidorovich V. E., Savchenko V. V. and Budny V. B. 1995. Some data about the European mink Mustela lutreola distribution in the Lovat river Basin in Russia and Belarus: Current status and retrospective analysis. Small Carnivore Conservation 12: 14-18.

Steinmetz B. and Muller R. 1991. An atlas of fish scales and other bony structures used for age determination. Samara Publishing, Gardigan: 1-212.

Tumanov I. L. and Smelov V. A. 1980. Feeding relationships of mustelids in north-eastern of Russia. Zoologicheskiï Zhurnal 59: 1536-1544. [In Russian with English summary]

Weber D. 1989. The diet of polecats (Mustela putorius L.) in Switzerland. Zeitschrift für Säugetierkunde 54: $157-171$.

Zhukov P. I. 1965. [Fish in Belarus]. Nauka i Tekhnika, Minsk: 1-414. [In Russian]

Zhukov P. I. 1988. [Reference book on freshwater fish ecology]. Nauka i Tekhnika, Minsk: 1-310. [In Russian]

Received 15 January 1998, revised 10 September 1999, accepted 20 September 1999. 